Historic, Archive Document

Do not assume content reflects current scientific knowledge, policies, or practices. 



\section{A Catalog of}

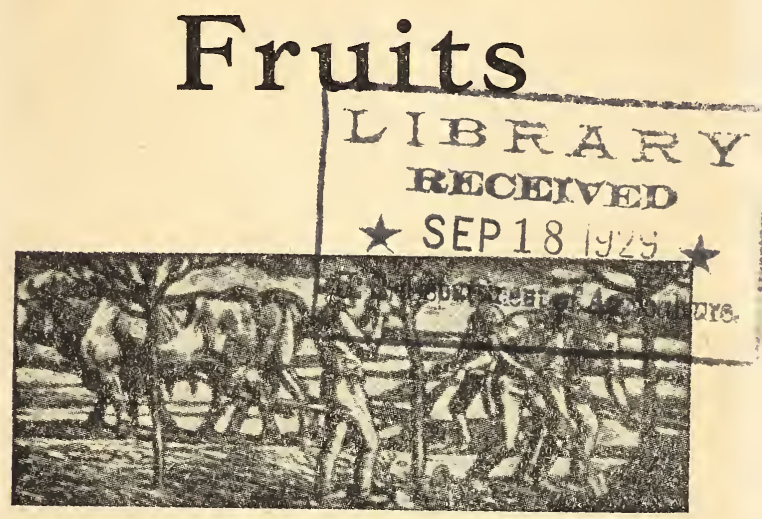

ORIGINATED AT THE

New York Agricultural Experiment Station

For Sale by the

New York Fruit

Testing Association

Geneva. New York 


\section{DIRECTORS}

B. D. Van Buren, President, Niverville

L. J. Clifton, Vice-President, Memphis

M. C. Burritt, Hilton

U. P. Hedrick, Geneva

Fred A. Smith, Hawthorne, Mass.

George A. Morse, Williamson

Frank B. Smith, Castleton

Richard Wellington, Sec.-Treas., Geneva

Harry L. KInG, Mgr., Geneva

1929-30 


\section{INTRODUCTION}

The plants of all hardy fruits are deficient in one character or another. There is no variety the fruit of which cannot be improved in size, color, capacity to keep, or in that combination of texture, flavor, and aroma, which constitute quality.

In particular, there is need of varieties of better quality. Orchards should contribute appetizers, health regulators, relishes, and desserts to increase the pleasure and healthfulness of the diet of millions. The better the quality, the better these purposes will be served and the greater the demand for fruits.

Again, the fruit industries of the country suffer terribly from unpreventable diseases. Unless some pear more resistant to blight, or some raspberry comparatively immune to mosaic, can be bred the profitable culture of these fruits is impossible. Similar problems of immunity present themselves with all other hardy fruits.

Once more, if fruits could be evolved to serve new purposes, the betterment of fruit growing would be great. As examples: Commercial canners want only yellow-fleshed, clingstone peaches which we do not but could grow in the East were good varieties available. So, also, canners want a firm, red-fleshed strawberry, characters not suffciently well developed in any of the sorts of this fruit.

The New York Agricultural Experiment Station has undertaken the tasks in breeding that have been suggested, with others scarcely less important. The fruits which originate at the Station are sold by the New York Fruit Testing Cooperative Association, Incorporated, Geneva, New York.

Any fruit-grower in any part of the world may become a member of this organization by paying a membership fee of one dollar and signing the by-laws. Application for membership should be made to the Association. All members whose dues are paid will be given a free premium on request. 


\section{APPLES}

Types of apples come and go. Russets, once much sought for in several varieties, are not now wanted. Green apples of all kinds are steadily losing in public favor. Baldwin and its similar sorts are falling below the mark in popularity. At present, McIntosh and Delicious types of apples are finding greatest favor in apple markets. Yet all of the varieties of these two types have their faults or do not fully cover apple seasons and purposes. This Association is offering several new varieties of each with the hope that they will prove valuable additions to McIntosh and Delicious.

\section{CARLTON (ASTRACHAN NO. 2391)}

Carlton was produced by crossing Montgomery, an attractive red apple, with Red Astrachan. The fruit ripens one month later than Red Astrachan and is large, round-conic, and attractive dark red to scarlet. The flesh is white, tender, juicy, subacid, and of Astrachan flavor. The tree is vigorous and bears annually.

\section{CORTLAND}

Cortland is a type of McIntosh that is gaining in popularity each year. The fruits of the two varieties are very similar but those of Cortland are more oblate and flatter across the base than those of McIntosh; they average larger and are more uniform in size; they have more color and the red is lighter and brighter and the stripings and splashes are laid on differently; the taste can hardly be distinguished from that of McIntosh; the flesh is firmer but just as juicy; the season is several weeks later; the apples do not drop so readily and ship better. The trees of the two varieties are much the same, differing chiefly in more slender and willowy branches in Cortland. From this comparison it will be seen that Cortland is an improved McIntosh especially desirable for late keeping, and as a good shipper.

\section{$\checkmark$ EARLY MCINTOSH}

Fruit growers are in need of an early red apple of good quality. Such an apple would sell well in all markets, and would be particularly valuable for roadside booths. Nearly every one knows McIntosh and likes it out of hand or 
however served from the kitchen. It is hardly too much to say that it is about the best general purpose apple in New York. Who can name an early apple with fewer faults of fruit than a McIntosh ready to eat in August? That is what Early McIntosh is. Besides pleasing the taste, this early apple pleases the eye. The red is handsome; the uniform round-oblate shape is most attractive and permits packing in various packages in which the apples fit well and look well. The appearance of the fruit is similar to that of McIntosh and the flavor is good although less aromatic. The trees are vigorous, hardy, healthy, productive, and bear annually. The parents of Early McIntosh are Yellow Transparent and McIntosh. The light color of the wood and the large leaf betoken Yellow Transparent; the shape and framework of the tree, especially the heavy-butted branches, are like those of McIntosh. The crop ripens a week or ten days later than that of Yellow Transparent and hangs on the tree as well as that of any early apple-quite as well as that of McIntosh.

\section{LODI}

Lodi originated at the New York Agricultural Experiment Station as a cross between Montgomery and Yellow Transparent and was introduced by this Association in 1924. The tree is of the type of Yellow Transparent, but draws upon Montgomery for increased vigor and size. The fruit is of the type of Yellow Transparent but larger, ripens a little later, thus prolonging the season of that variety; and while sprightly for use in the kitchen, as it commences to ripen the flavor becomes milder and pleasantly aromatic. The variety is an improvement over Yellow Transparent in that the tree is better, and the fruit is larger and keeps longer.

\section{$\checkmark$ MACOUN}

Just as Early McIntosh advances the season for the McIntosh type of apple, Macoun produces a late crop of these red-skinned, white-fleshed, richly flavored, aromatic apples. The season of Macoun is from one to two months later than that of McIntosh with Cortland midway between. In shape, the fruits of Macoun are similar to those of McIntosh; the color is a darker red, less striped, and with a heavier bloom; the flesh is much the same in color, texture, flavor and aroma. The trees bear regularly and heavily. This promises to be an apple of great merit coming in, as it does, long after all other McIntosh-like apples are out of season.

\section{$\checkmark$ MILTON}

Milton is a sister of Early McIntosh which ripens its crop a month later. Its main value is that it is a McIntosh 
type which ripens a month before McIntosh. The tree is vigorous but not as large as that of Early McIntosh. The fruits are covered with a very attractive pinkish red and heavy bloom. The flesh is white, tender, crisp, juicy, and of McIntosh flavor and aroma.

\section{MEDINA}

Medina originated at the New York Agricultural Experiment Station as a cross between Deacon Jones and Delicious and was introduced in 1923 by this Association. The variety promises well as an apple of the Delicious type to prolong the season of that variety. In appearance the apples resemble those of Delicious closely but are much larger, and are more attractive on account of the golden yellow ground color which the fruits of Delicious rarely develop. The shape of the basin is like that of Delicious with the same deep corrugations and the five distinct crowns.

\section{$\checkmark$ NEWFANE}

Newfane is the last of the Deacon Jones by Delicious crosses to be introduced. It was selected for trial on account of its large-sized fruit and very attractive dark solid red color. The shape is oblong conic and the flesh tender, medium juicy, mildly flavored with a pronounced Delicious aroma. This apple is a good dessert apple and ripens about Christmas time.

\section{ORLEANS}

Orleans is a sister plant to Medina and was introduced a year later. The variety is of the Delicious type but the fruits are more attractive in appearance and run larger. While Orleans comes in season about with Delicious, it keeps in common storage six weeks longer. The fruit has the same rich delicious taste that characterizes Delicious, but the flavor is more sprightly. Orleans is very similar in tree and product to Medina but besides keeping longer may thrive in some soils to which Medina is not adapted.

\section{RED GRAVENSTEIN*}

This red sport of Gravenstein is offered by the New York State Fruit Testing Association as a more attractive apple than Gravenstein. It differs from the old Gravenstein only in the solid, dark red colored fruits, the parent fruit being light red and much striped with yellow and green. Banks Gravenstein another sport of Gravenstein is also striped, and much lighter in color than Red Gravenstein, altho handsomer than the original variety of this type. All of these Gravensteins are most excellent autumn apples, but the new one is so much superior in appearance that in the future its culture alone of these three should be recommended. 


\section{RED SAUCE}

Red Sauce is a cross between Deacon Jones and Wealthy. The fruit is large, roundish conic, nearly covered with solid red. The flesh is coarse, tender, crisp, juicy, briskly subacid, aromatic, and red to the core-lines making a red sauce when cooked. The apples are too tart for dessert but are excellent for culinary purposes. The crop ripens in October and November.

\section{RED SPY*}

Red Spy is a typical Spy except in color. The color is a solid bright red without either stripes or splashes. The new variety has the serious fault of the parent, that of coming in bearing late, but there are many good characters to offset this fault. Thus, there are delectable quality and great beauty in the fruits, and in the tree hardiness, healthfulness, productiveness, and reliability in bearing. Nor should it be forgotten that the trees are long-lived, nearly perfect orchard plants, and that they bloom very late thereby often escaping late spring frosts which ruin the crops of other varieties. Northern Spy is still one of the best apples for New York, and Red Spy, with its beautiful fruits, should give new life to this old sort.

\section{STATION NO. 3609}

This is a sweet apple which was produced by crossing Zusoff, a sprightly, dark red apple, with McIntosh. The fruit ripens a little before McIntosh and is large, roundish oblate, handsomely colored with dark solid red and heavy bloom like McIntosh. The white flesh is often stained with red and altho coarse in texture, is tender and juicy with an aromatic sweetness which makes the sort especially desirable for baking. The tree is hardy and productive. There have been so many requests for trees of this seedling that its limited propagation seemed warranted.

\section{$\checkmark$ SWEET DELICIOUS}

Sweet Delicious originated at the New York Agricultural Experiment Station as a cross between Deacon Jones and Delicious and was introduced in 1923 by this Association. The fruits resemble Delicious in shape, but the lipping of the stem and the dull grayish scarf skin over the surface are characters inherited from Deacon Jones. The apples are large and attractive in size, color, and shape, with the sweet aromatic flavor of Delicious. The variety is an apple for home use where it will be chiefly appreciated for dessert and baking. Its season is a little later than that of Sweet McIntosh to be described next. 


\section{SWEET MCINTOSH}

Sweet McIntosh originated at the New York Agricultural Experiment Station in 1910 as a cross between Lawver and McIntosh and was introduced by this Association in 1923. Externally the fruit resembles Lawver rather more than McIntosh, but the sweet flavor plainly suggests McIntosh. The variety is, of course, primarily adapted for home use-for baking and to eat out of hand. It should become a splendid home and roadside market sort.

\section{CRAB APPLES DOLGO*}

This handsome red crab apple was imported from Russia in 1897 by Professor N. E. Hansen, of the South Dakota Experiment Station. The fruit is full of juice, jells easily, and makes a rich ruby-red jelly of beautiful color and excellent flavor. The tree is hardy, vigorous, and productive and ripens its fruit early in September.

\section{YOUNG AMERICA*}

This crab apple, of unknown parentage, produces abundantly most attractive red fruits of excellent size and quality. While Dolgo is oblong conic in shape this variety is roundish conic and attains a larger size than does Dolgo or Hyslop. Jelly made from the fruit is clear, attractive red and splendidly flavored. The tree is especially vigorous and hardy. The season is about the middle of September.

\section{CHERRIES}

In the breeding of new cherries, the New York Agricultural Experiment Station has so far accomplished but little in a field where much might be done. But one cherry bred at the Station can be offered, but this one-Seneca-is especially meritorious as a reading of its description will show. Fortunately, however, several other noteworthy new cherries, all of which have been thoroughly tested on the Station grounds, can be offered by the Association to cherry growers.

\section{ABUNDANCE*}

Abundance is a splendid late cherry of the Napoleon type. The cherries are a little smaller than those of the well-known Napoleon, about the same in quality, but ripens from one to two weeks later, and the cherries seldom crack as those of Napoleon too often do. To be more 
specific as to characters; the fruits are large, round-cordate, yellow-amber, mottled with red; the flesh is whitish, juicy, crisp, firm, sweet, rich, and aromatic; the stone clings to the flesh. The tree characters are all good. This is the latest cherry of the Bigarreau type. Further good qualities are that the cherries are not susceptible to rot, and, for some reason, the thieving robin is not fond of it.

\section{CHASE*}

Chase is a late black sour cherry of the Morello type. At Geneva the tree is larger, healthier and more spreading than that of the English Morello. The fruit is larger and has a shorter stem and is milder in flavor. Chase ripens a few days earlier than English Morello.

\section{$\times$ GIANT*}

Giant originated with Luther Burbank in 1900 and was introduced in 1914. The variety shows many characters that commend it. The tree is large, vigorous, and very productive. The cherries are attractive in size and color and about the latest of all cherries to ripen, coming in season just before Lambert which it resembles in size and color. The quality is splendid and the cherries do not crack as do those of so many other sorts and, therefore, should keep and ship well. Giant seems to be a splendid new sort.

\section{LYONS*}

Though grown for more than a century in Europe, Lyons seems never to have been tried extensively in America, possibly because it was not considered particularly valuable in the Old World. Of the many sweet cherries tested on the grounds at this Station during the past twenty years Lyons is one of the best sweet cherries. It should be planted for an extra early market cherry, and is one of the few early sweet cherries that gives promise of standing handling for distant markets. The tree characters are about all that could be desired in a sweet cherry.

\section{PRUNUS TOMENTOSA*}

Prunus tomentosa is a beautiful dwarf cherry from northern China, the leaves of which are covered on the under side with tomentum, hence the name. The fruits are small, round, bright red, and similar to those of Montmorency in flavor. The plant is beautiful in leaf, flower, and fruit.

\section{SENECA}

Seneca is a new cherry of promise, and it is so remarkable in one character at least, earliness, that it is bound to be a great acquisition to cherry growing. Its fruits ripen in the 
first weeks of June, more than two weeks earlier than Black Tartarian, the standard early cherry in New York. The cherries resemble those of Black Tartarian-large, roundcordate, purple-black, with juicy, melting flesh, and a rich, sweet flavor. The pit is free and the skin does not crack. The tree is very vigorous, productive, and has an upright-spreading habit of growth. Seneca originated on the grounds of the New York Agricultural Experiment Station and was introduced in 1924.

\section{VICTOR*}

Victor is an open-pollinated seedling of Windsor which originated in 1916 at the Horticultural Experiment Station at Vineland, Ontario. The fruit resembles Napoleon in appearance and ripens midway between the season of that sort and Governor Wood. The cherries are large, firm fleshed and light colored like Napoleon and of excellent quality. The tree is large, vigorous, and productive.

\section{NECTARINES}

Nectarines are little grown in New York chiefly because the curculio usually plays havoc with the crop. The curculio, however, is easily controlled by spraying. The nectarine is a smooth-skinned peach and the skin is in no way objectionable as is the fuzzy epidermis of the peach; the flesh is usually sweeter and richer. Certainly nectarines would add variety to the list of fruits for New York if there were suitable varieties. It seems desirable, almost imperative, that the New York Agricultural Experiment Station try to breed better nectarines.

\section{HUNTER*}

Hunter is the first sort to be offered. The tree is large, vigorous, hardy, healthy, and productive. The fruits are large, handsomely colored, and very good in quality. Hunter is being sent out as the best midseason nectarine for New York.

\section{JOHN RIVERS*}

An English nectarine which is the earliest variety tested at the New York Agricultural Experiment Station. Its fruit is medium in size, nearly covered with red, attractive and good in quality. The flesh is white, juicy, and adherent to the stone. John Rivers is well worthy of trial and extends the nectarine season. 


\section{QUETTA*}

A large, white-fleshed, clingstone nectarine introduced from Quetta, India, by the Bureau of Plant Industry, Washington, D. C. Quetta is being planted commercially in California, but in New York it is recommended only for trial.

\section{SURE CROP*}

This nectarine was imported from New Zealand by the United States Department of Agriculture. The fruit is large, bright red, and of very pleasing flavor. The tree is hardy and productive. The flesh of the fruit is white, juicy, fine grained, tender, sweet, aromatic, and very good in quality. The stone is free and the fruit ripens early in midseason. This has been the best white-fleshed nectarine tested on the Station grounds.

\section{$\mathrm{PEACH}$}

\section{MIKADO*}

All growers of commercial peaches want an early yellow-fleshed peach. On the grounds of the New York Agricultural Experiment Station, Mikado fills this place better than any other variety. The fruits are large, handsome, and blushed on the sunny side. They begin to ripen in early August and all mature at the same time, the fruits running very uniform. The quality is good for a peach of its type, nearly all agreeing that the flavor is bet; ter than that of Elberta. The trees are vigorous, hardy, and productive. If it turns out that Mikado has to any great degree the character of adaptability to a great diversity of soils and climates as has Elberta, this new variety will be a great addition to peach growing in New York. This sort was introduced as June Elberta, but the correct name is Mikado.

\section{PEARS}

The chief end sought in breeding pears at the New York Agricultural Experiment Station is to obtain varieties less susceptible to blight than any of the standard commercial sorts now grown. Seckel, being fairly free from blight, and with splendid tree and fruit characters is the parent that has been most commonly used. Several Seckel seedlings are now being propagated as in some measure meeting the requirements set for a variety of sufficient merit to be introduced. It will be a surprise to fruit growers to know the 
number of seedlings discarded from the plantings which have given eight kinds worth a second trial -more than 2,000 seedlings have been rejected, or about 250 discards to 1 saved.

\section{CAYUGA}

Of the promising seedlings of Seckel, one has been named Cayuga and is being distributed. The tree characters of this new sort on the Station grounds seem to be about all that could be desired. The young trees are vigorous and healthy. The pears average as large as those of Bartlett but in shape are similar to Seckel and in color to Clairgeau. The flesh is firm and fine in texture quite to the center, with the rich, delectable flavor of Seckel. It is not too much to say that the quality is better than in any other standard sort excepting Seckel.

\section{EWART*}

This pear was received more than 15 years ago by the New York Agricultural Experiment Station from Mortimer Ewart of East Akron, Ohio. The fruit has attracted considerable attention owing to its large size and good quality. As several growers have wished to secure trees, the Association has propagated a limited amount of stock, thanks to Mr. Ewart's courtesy. The fruit is greenish yellow, netted with russet, and has a fine, melting, tender, juicy flesh. The season is about one month later than Bartlett.

\section{$\checkmark$ GORHAM}

Pear growers want a variety to follow Bartlett which lacks some of the conspicuous faults of the several sorts that are now grown for that season. Gorham now offered by the New York Fruit Testing Association ripens its fruits two weeks later than Bartlett, and these keep a month longer. The fruits resemble those of Bartlett in size, color, and shape. The flavor is sweet and vinous with a very marked and pleasing aroma. The flesh is white, tender, buttery, and juicy-a combination which, with the rich flavor and spicy aroma, make this one of the very best flavored pears of its season. Whether Gorham will resist blight can not be said-but as yet it has not blighted on the Station grounds. The trees are vigorous and productive.

\section{PHELPS}

Phelps is a cross between Winter Nellis and Russet Bartlett which originated at the New York Agricultural Experiment Station in 1913. It was introduced by this 
Association in 1925. The fruit is of the type of Bartlett but ripens much later. The flavor is better than that of Bartlett, but the appearance of the fruit is duller. The flesh is tender and juicy with a pleasant vinous flavor. It ripens around Thanksgiving and keeps until Christmas. The variety prolongs the season of Pulteney which in turn prolongs that of Bartlett.

\section{PULTENEY}

Pulteney originated as a sister plant to Phelps and was introduced in 1924 by this Association. The fruit is of the Bartlett type, a little more regular in outline, skin smoother, but possibly not as attractive in color. Its season is four weeks later than that of Bartlett, and continues until Phelps starts to mature. The chief fault of the fruit is in the dullness of the color; the pears do not become yellow until very ripe and seldom have the attractive blush of Bartlett.

\section{PLUMS}

One hesitates to recommend new plums for in New York, at least, the culture of this splendid fruit is on the wane. This is partly the fault of the growers of plums, since for years they have supplied the markets with varieties, such as Lombard and Bradshaw, which no one would choose to eat as dessert after a first attempt and which are none too good in cooked products. Probably, however, the competition with westerngrown plums, which are larger and handsomer, is the chief cause of the dull market for New York plums. It may be that a large, handsome plum of prime quality might be profitably grown in this State. Certainly such a plum would sell on roadside markets. To stimulate anew the growing of plums in this region, if possible, this Association offers Albion and Stanley, two of the best and handsomest plums in a collection of over 300 varieties. grown on the grounds of the New York Agricultural Experiment Station.

\section{ALBION}

Albion, a cross between Golden Drop and Grand Duke, is the latest ripening good plum grown at Geneva. It belongs to the Grand Duke type, but its fruit is larger and better in quality. The tree is productive, strong, and 
vigorous. In consideration of its desirable characteristics, Albion is recommended for trial.

\section{AMERICAN MIRABELLE}

The Mirabelle is a small sweet yellow plum which belongs to the same species as the Damsons, from which they differ in color and flavor of fruit, and but little or not at all in tree. There are several Mirabelles in Europe, much liked for dessert and culinary purposes, but none are grown in America, growers having objected to the small fruits. The fruits of American Mirabelle resemble those of the Mirabelles closely in color, but are much larger. The tree is splendid in every way. The flavor is delightfully good and the new variety will be appreciated by all lovers of choicely good fruits.

\section{APEX PLUNCOT*}

This fruit is said by Burbank, its originator, to be a cross between a plum and an apricot, but on the Station grounds it seems to be a pure-bred Japanese plum. The fruits are large, round-ovate, light red with a lilac bloom and a thin tender skin. The flesh is yellow, juicy, mild, and sweet with a slight a pricot flavor. The stone clings rather tenaciously. The variety is recommended for home gardens.

\section{BEAUTY*}

Beauty is an early Japanese plum that precedes Abundance. The fruits are medium in size, roundish conic, medium to dark red, and covered with a lilac bloom; skin thick and tough; flesh yellowish tinged red, very juicy, tender but stringy, subacid to sweet; good; clingstone. Recommended for home use and roadside market.

\section{FORMOSA*}

Formosa is a Japanese plum recommended on account of its productiveness and large fruits. The fruits are oval to slightly cordate, greenish yellow nearly overlaid with red; flesh firm, juicy, melting, pale yellow, sweet, and good; stone slightly clinging; ripens midseason.

\section{HALL}

Hall is a cross between Golden Drop and Grand Duke, two of the largest and handsomest European plums, but both below the mark in quality, while Hall is better in flesh and flavor characters. It does not resemble Golden Drop in shape or color but in these characters is similar to Grand Duke. The fruits are so handsome and wellflavored that they should sell in either roadside or city markets. 


\section{IMPERIAL EPINEUSE*}

This is an old French plum of the prune type, reddish purple, tender, sweet, juicy and one of the best flavored of the Old World plums. It ripens late and so often escapes brown rot. The trees grow wonderfully well in the East and the variety should be much more widely grown than it is.

\section{PRESIDENT*}

President is a very late European plum that is attracting much attention in California and deserves trial in the East. The fruits are large, oval, dark reddish purple, with thin bloom; skin medium thick and tough; flesh greenish yellow, firm, medium tough, subacid to sweet; good; nearly a freestone.

\section{SANNOIS*}

Sannois is a very late reddish-purple French prune of medium size. It is one of the sweetest and most delectable varieties of all the plum family. Recommended for home garden on account of excellent quality.

\section{SANTA ROSA*}

Santa Rosa is one of the new and noteworthy Japanese plums which in many characters of tree and fruit surpasses Abundance and Burbank. The tree is a prolific bearer, and the large attractive fruits keep and ship well. It has long been considered about the best of the Japanese plums on the grounds of the New York Agricultural Experiment Station.

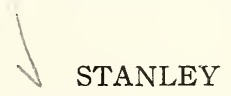

Stanley originated on the Station grounds in 1913 as a cross between Agen and Grand Duke. The fruit is of the prune type and should be excellent for cooking or eating out of hand.' The tree is healthy, vigorous, and produces full crops annually. The tree is medium size, vigorous, upright spreading, open vase form, productive./ The fruit is above medium to large in size, prune shape, dark blue with thick bloom; stem long, glabrous; skin medium in thickness and toughness, not cracking; flesh greenish yellow, moderately juicy, fine grained, tender, firm, sweet, pleasant; quality good to very good; stone free; midseason, or three days earlier than Grand Duke or a week to ten days earlier than Italian Prune.

\section{GRAPES}

All of the men who have undertaken to improve native grapes, and there have been many, have 
chosen as their chief task hybridization with the European grape to obtain a combination of the fruit characters of the European grape with the vine characters of American grapes. Of the twenty-odd thousand hybrid grapes grown on the grounds of the New York Agricultural Experiment Station in the last twenty-five years, possibly three-fourths of the total number have been made with this end in mind.

\section{BROCTON}

Brocton is a green dessert grape suitable for home use and local markets. The flesh is melting, separates readily from the seeds and is sweet, richly and delicately flavored. In berry, season, and flavor, the fruits are of the Diamond type, but the bunches are larger. The vine is not so vigorous as might be wished, is rather slow in growth, and is inclined to bear too heavily, for all of which reasons it should have special care in culture and pruning.

\section{$\checkmark$ DUNKIRK}

Asked to name the grape of grapes for market and home, nearly all would say Delaware. But the vines are small, slow of growth, susceptible to mildew, capricious as to soils, and bunches and berries are small. One of the aims in grape breeding is to produce varieties similar to Delaware without the faults that have just been named. Dunkirk is sent out to fill this place. Bunches and berries of Dunkirk are similar to those of Delaware, but both are larger, and the crop ripens later and keeps longer. The skin is thin like that of Delaware, but is tough enough to make the grapes good shippers. The clusters are unusually uniform in shape and size, compact and well filled by the berries. The vine is vigorous, hardy, healthy and in the Station vineyard very productive.

\section{a FREDONIA}

Fredonia gives promise of being our earliest good black grape. The vine is vigorous, hardy, and productive and ripens its fruit two weeks earlier than Worden. Its quality is superior to its parents, Champion and Lucile. The clusters are medium in size, cylindrical, and compact; the berries large, round, and persistent; the skin thick and medium tough; the flesh juicy, solid but tender; and the quality very good.

\section{GOLDEN MUSCAT}

Golden Muscat is a cross between Muscat Hamburg and Diamond. It possesses the rich golden color of the Dia- 
mond and the fine muscat aroma of the European parent. For home use and the roadside market it is one of the best. Possibly the skin is too tender for shipping. The vine is vigorous, productive; the clusters are very large, tapering, single shouldered, and compact; the berries are large, oval, juicy, tender, sweet, vinous, aromatic, and ripen about with Concord.

\section{HANOVER}

A red grape produced by crossing Brighton with Niagara. Clusters medium to large, and moderately compact; berries medium, slightly oblong, dark red flesh slightly tough, sweet, vinous, and good in quality. This seedling which ripens about October first, has been fruiting at Geneva and Fredonia for 25 years and has shown sufficient merit to warrant a trial under other conditions.

\section{KEUKA}

Keuka is a cross between Chasselas Rose, a European grape, and Mills, a hybrid between an American and a European. Thus, the variety is more nearly a European than a native grape, and this the fruit shows in every character. Bunch and berry are but medium in size, but the bunch is compact and as trim as a well-formed cluster of Delaware. The berries are round-oval, dark red with heavy bloom which gives them a lilac color. The flesh is crisp and juicy with a sweet, vinous, Vinifera flavor, and scarcely separates from the tender skin so that the berries may be eaten skin and all as are those of all Vinifera grapes. The vines are vigorous, healthy, productive, and hardy and ripen their crop at least two weeks earlier than do those of Catawba.

\section{$\checkmark$ ONTARIO}

Ontario is a cross between Winchell and Diamond which comes in season a little before Winchell, hitherto the best early green grape. Bunches and berries are larger and more attractive in appearance than those of either of the parents, the bunches are not quite so compact, and unlike those of either parent are usually single shouldered. The vines are more vigorous and more productive than those of Winchell or Diamond. The grapes hang on the vines long after ripening.

\section{PORTLAND}

Ontario, described above, takes first rank as an early green grape for home use, and Portland, ripening at about the same time, holds first place among the grapes as an early green variety for the market. The vine in this variety is particularly satisfactory, as it is very vigorous, hardy, 
productive, and healthy. The variety is remarkable for its luxuriant and persistent foliage. Bunches and berries are larger than those of any other early green grape and quite equal in size to the bunches and berries of Niagara. The quality is better than that of any other native green grape excepting Ontario which it does not equal.

\section{SHERIDAN}

Sheridan is a promising late-keeping grape to extend the season of Concord. In many places where Sheridan has been grown under the same conditions as Concord, the plants have been found to be just as vigorous, healthy, hardy, and more productive. The bunches of Sheridan are larger and more compact, with a firmer skin, and berries as large as those of Concord; the flavor is sweeter and richer. The season is a week later and the grapes do not shell as readily, so that the crop can be kept longer than that of Concord. It only remains to be seen whether or not Sheridan will thrive in as great diversity of soils as Concord.

\section{URBANA}

Urbana promises well for both home and market where it matures. Unfortunately it requires a long season and cannot be grown with certainty where Catawba does not ripen as it is a few days later than that variety. The vines are vigorous, healthy, and productive, and will withstand as much cold as Catawba or Delaware. Bunch and berry are large and both are very attractive. The berries are large, oval, light red, with rather thick skins which cling to the pulp like that of a Vinifera, and the flesh separates readily from the two or three rather small crackling seeds. The flesh is firm but tender, juicy, aromatic, and has a rich, sweet, vinous, spicy, refreshing flavor. The grapes keep in common storage without shrivelling, shelling, or decaying until March, and this, possibly, is the character that should commend Urbana most highly to grape growers.

\section{WAYNE}

This grape was obtained by crossing Mills with Ontario. The vine is strong, vigorous, and productive; clusters medium to above in size, and compact; berries above medium, oval, and reddish black; flesh medium firm, slightly tough, juicy, sweet, vinous, with slight Mills flavor; quality very good; skin thick, and tough. Well worthy of trial but its keeping quality is impaired by a tendency to shell.

\section{ELDERBERRY}

\section{ADAMS*}

This variety is a selection made by the late William $\mathrm{W}$. Adams, Union Springs, N. Y. The bush is strong, vigorous, 
and productive aand the fruit clusters are exceptionlly large.

\section{GOOSEBERRIES}

The culture of gooseberries has long been on the wane in New York chiefly because nurserymen choose to offer only the wretchedly poor Downing and Houghton. At this Station, the aim has long been to obtain gooseberries with larger fruits, of better flavor, and of better plant characters than the two old sorts which years ago were past usefulness. Poorman was introduced a number of years ago as a better gooseberry, and where it succeeds is a most admirable sort. Unfortunately it does not do well on sandy soils, thriving only on clays and fertile loams. Now the Station is introducing Fredonia with the hope that it will be more adaptable to soils.

\section{FREDONIA}

The berries of Fredonia are large, attractive in appearance, and the ripe fruits rank high in quality. The plants are healthy, vigorous, and on the Station grounds free from the gooseberry mildew which is the bane of the large-fruited gooseberries introduced from Europe.

\section{RASPBERRIES}

It is apparent that unless varieties of red and black raspberries resistant to mosaic and other diseases can be bred that the production of these fruits must cease to be profitable in this state. The Station is giving its utmost attention to procuring varieties of these fruits resistant to disease - with what success remains to be seen. The Association offers several varieties, however, which seem to be resistant and which are most admirable in every other particular. Canners want a good standard purple variety, better than any now grown in this state. This Station is attempting to breed such a sort. Two varieties much better than any other purple are now offered by the Fruit Testing Association. 


\section{BRANT}

Now that red and black raspberries are less grown because of the several diseases which make their culture precarious, fruit growers are looking for good purple sorts, and consumers of the fresh berries more and more find purple berries acceptable substitutes for the reds and blacks. Brant is a new berry far superior to any other purple sort both in plant and fruit characters. The plants are highly resistant to raspberry diseases, and the fruits are large, handsome, firm, hold up well, and are of very good quality. Brant is a cross between Smith and June and was introduced in 1925 by this Association.

\section{$\checkmark$ DUNDEE}

Dundee originated in 1911 as a cross between Smith and Palmer. This is one of the most promising black-caps on the Station grounds, the fruit being of large size, glossy, attractive, and of excellent quality. The berries are not as firm as those of Plum Farmer, but are of a more pleasing flavor and appearance and ripen at the same time as that variety. The plants are tall, vigorous, upright, spreading, and very productive. The fruits are uniformly large, regular, roundish conic to roundish with a light bloom; drupelets numerous, small, cohering strongly; color glossy black; flesh juicy, tender, firm, not seedy, mild subacid becoming sweet when fully ripe; very good; midseason.

\section{$\checkmark$ LLOYD GEORGE*}

Lloyd George is the only English raspberry that has ever succeeded on the Station grounds, most of them suffering severe winter killing, or not withstanding the hot summer sun. The plants are stocky, of medium height, and the dark green foliage is conspicuous in a variety collection. The fruit is very large, averaging seven-eighths of an inch in length on the earlier pickings, rather soft and dark if fully ripe, sprightly, and of excellent quality. It is somewhat hidden in the foliage, making picking more difficult than with other berries. Lloyd George is recommended for trial for home use and local markets. It seems to prefer the heavier soils and a cool, moist climate.

\section{NEWBURGH}

Newburgh, a cross between Newman and Herbert, is offered for the first time this year. The plants are vigorous, hardy, and very productive. Mosaic has not yet appeared in the stock of this variety. The fruit is very large, very firm, and should ship unusually well. The flavor is mild and the quality fair to good. Like its parent, Newman, the berries cling to the bush more than is desirable, but 
because of the firmness and dryness of the fruit, may be picked without seriously injuring the fruit. In season it is three or four days earlier than Cuthbert.

\section{NEWMAN*}

Newman is one of the most remarkable red raspberries of recent introduction because of its large, handsome berries which are borne in great profusion. On the grounds of the New York Agricultural Experiment Station, Newman is the most productive of the hundred or more red raspberries now being grown. The berries are firm and ship well. The plants are vigorous, hardy, and healthy. The character that commends Newman most highly, however, is that it is almost free from the mosaic disease which troubles other raspberries so seriously in all parts of the country.

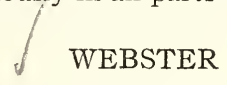

Webster originated in 1911 as a cross between Smith and Louboro. Webster is one of the most promising purple raspberries on the Station grounds. Its merits are productivity of the plants and the freedom from mosaic, very few diseased plants having been found in the stock of this variety during all the time it has been under test. The fruit is of good size, sprightly and fairly good in quality. The plants are medium in size, vigorous, upright, above medium to large in size, roundish, dull purple, drupelets numerous, medium size, cohering well; flesh medium juicy, firm, sprightly; quality good; season late, about with Columbian.

\section{STRAWBERRIES}

In past years, the New York Agricultural Experiment Station has sent out a number of seedlings, several of which have been considered worthy of trial, but none of which have been remarkable sorts. The three sorts, however, now offered by this Association from the Station are more productive on the Station grounds than any other sort of their season. Strawberry growers ought, by all means, to try these because of the handsome, well-flavored fruit and vigorous, productive, healthy plants.

\section{BEACON}

Beacon is one of the best early strawberries. The crop ripens with that of Dunlap, long a standard early kind, and packed for market, it is about the handsomest early straw- 
berry grown on the Station grounds. The berries hold up well thruout their season in spite of drought or other adverse conditions. The quality is excellent. The plants are numerous, healthy, and productive, very large and vigorous, and are characterized by long pedicels which make picking easy. The flowers are perfect.

\section{$\sqrt{ }$ BLISS}

Bliss is recommended as a late midseason strawberry for home or market. The berries are large, handsome, bright red, glossy, uniform in size and shape, and color evenly. The flesh is well colored to the center and is a pleasant commingling of sweetness, richness, and sprightliness, which makes it among the best in flavor. The plants stand as high in essential characters as any of the commercial varieties of the same season, and in one respect surpasses most of its garden associates-the variety withstands drought well and there are few small berries when the soil is parched with dry, hot weather.

\section{BOQUET}

Boquet ripens about midway between Beacon and Bliss. These three new berries cover the strawberry season in New York. The berries of Boquet are characterized by their large size, blunt-conical shape, and by the compact clusters at the ends of the fruit-stems. The berries are uniformly colored a light red, and the flesh is well colored to the center. The berries are rich, sweet, and refreshing. The fruits ship excellently and keep well, in these respects averaging far above the common run of commercial strawberries. The plants are vigorous, productive, and healthy, withstand drought well, and produce an unusually large number of big and handsome berries.

Prices of varieties listed in this catalog will be sent on application. 


\section{NOTES IN REGARD TO POLLINATION OF FRUITS}

Some varieties of fruit produce good crops when planted by themselves and are known as self-fruitful or self-fertile, while others set little or no fruit unless pollinated by other varieties. In order to avoid disappointments, the following recommendations are made for planting varieties mentioned in this catalog. Where a pollinator is required, solid blocks of over four rows width should be avoided.

Apples-It is advisable to set at least two varieties of apples in the same orchard and when Red Gravenstein is used, three varieties should be used, as the pollen of Red Gravenstein germinates poorly.

Cherries-All sweet cherries require a pollinator. Any combination of the listed varieties should prove satisfactory. Possibly Chase should be interplanted with either English Morello or Montmorency, although sour cherries are generally self-fruitful.

Peaches-Mikado should be interplanted either with nectarines or other peaches, but not with J. H. Hale.

Pears-All pear varieties require a pollinator. A combination of any two listed will prove satisfactory.

Plums-Generally speaking, the Japanese plums such as Formosa, Santa Rosa, and Beauty are selfunfruitful. Beauty, however, sets a fair crop when self-pollinated. At least two Japanese plums should be set near together and European plums cannot be depended upon as pollinators.

The European varieties vary in regard to selffruitfulness. Stanley and Sannois are self-fruitful, while Imperial Epineuse and President are selfunfruitful. Thus, it is advisable to set another variety such as the Stanley with the Imperial Epineuse.

The other fruits, such as grapes, elderberries, gooseberries, raspberries, and strawberries are selffruitful. 


\section{,}





\section{•}



"Forward in the name of God; graft, set, plant, and nourish up trees in every corner of your ground; the labor is small, the cost is nothing, the commodity is great; yourselves shall have plenty, the poor shall have somewhat in time of want to relieve their necessity, and God shall reward your good merits and diligence." 